\title{
Leadership perspectives on gender equality
}

\section{Editorial team}

We asked two focus groups of senior leaders in the University what they thought the key issues were about gender equality, how they felt things had changed and what they felt the priorities were for the future. Some were from academic departments, others professional services. Just over half were women and most of the group had worked at the University for many years. The discussions were frank and wide-ranging.

There was consensus that achieving gender equality required organisational change.

Equality is not about attending some training courses; it is a change programme for the workplace.

Another added:

You need to tackle gender inequality at different levels. There are significant structural barriers [as well as] dayto-day interactions. You need a systems level change.

\section{Recognising the problem}

One of the first people to speak said:

The first step is to recognise that you have a problem.

This was not always straightforward. Several senior women spoke of their experience of gradually adapting to a challenging environment until they stopped noticing it. 
I was the first woman appointed to chair in my department. There were the inevitable you only got the job because you are a woman' comments. There is a drip, drip, drip of undermining comments you face as a female academic. It just becomes normal.

Someone else said:

It can be hard to challenge behaviours that are so embedded that you stop noticing. Small everyday injustices... but tackling them is not only good for women but good for everyone.

The importance of workplace culture was mentioned again and again.

There can be cultural problems; you can have a macho culture and that is everything down to the way people talk, use their bodies, their sense of humour. You want to strike a balance, you want people to feel they can be themselves at work, and for different disciplines to have their own cultures but you need to be able to challenge stereotypes where they do exist and create an environment where people can be honest, be open. You need to avoid outsider vs insider.

A female professor in a maledominated field said:

Women coming into this field are more aware of the existing culture and you have to learn how to fit in. You often need to adapt. Men don't need to do this but persuading them of the value of being aware of the cultural norms and pressures can help people to see how hard it can be [ifyou're in the minority].

There was an acknowledgement that men can also feel like outsiders.

One benefit of Athena SWAN was also to look at subjects where men are in the minority. Gender imbalances are a two-way street.

People also referenced the challenges of overcoming wider societal expectations around gender roles.
Societal expectations can affect who takes 'parental' or family policies. Championing a wide range of role models is important.

Another mentioned that:

It is often male students who need more encouragement or who are more reluctant to ask for help.

The role universities play in society in educating the next generation for a diverse range of careers was another area to explore. Curriculum design is clearly of vital importance and it is helpful to be aware of the gender dimensions:

There are issues with gender in the curriculum. Who teaches what, how teaching is perceived by students, what is taught.

There are also challenges for student recruitment:

It is important to reflect on the gender balance of different sectors. How do you bring men into female-dominated workforces as well as increase the number of women in more male-dominated areas?

Another person said:

It is important that the initiatives we put in place as an organisation support positive action. We have to give equal access to opportunities at all times. We must avoid positive discrimination, though - that's both unfair and potentially harmful.

\section{Recognising your own biases}

In addition to noticing the wider culture or working environment, several people stressed how important it is to be aware of your own biases.

In your head you have someone in your own likeness, or an idea of a typical person in that field. I was asked to give suggestions of people who could be on an advisory board. They got back in touch to say all the suggestions I had provided were all men and could I suggest any women. And I'm a woman and that was me doing that! 
It's not that there aren't good women out there; it's just that [in] your mindset... they just haven't bubbled to the top.

Another person talked about bias in recruitment.

We were recruiting for an academic post. One candidate was a very eloquent man and you could hear comments from other panel members like: 'I could see myself working with him,' 'He reminds me of colleague x.' There was a female candidate who was more softly spoken. The panel's comments were things like: 'She has a very quiet voice; she won't be able to teach'. It was a long day of interviewing and by the end I felt too tired to reach a final decision. Coming back to it fresh the next morning was a chance to have a broader perspective. When I looked again at the CVs, reviewed the experience of the candidates and thought about the answers to the interview questions, it was obvious that the 'quiet' woman was better qualified for the role.

\section{External drivers}

Culture change is complicated, particularly in the context of a large, devolved and ancient university with many different communities and subcultures. Several people spoke of the value Athena SWAN has of providing an external push for change.

External drivers can galvanise action; Athena SWAN is a good example of this.

Another added:

You need a baseline to track progress. Athena SWAN is helpful with this.

External accreditation like Athena SWAN can provide some structure for a systems level approach to change and is implemented alongside other HR (Human Resources) policies which aim to achieve a workplace which is fair to all. While everyone acknowledged the importance of fair processes for recruitment, workload allocation, promotion, performance management and reward, just adopting appropriate processes is not always enough.

\section{Recruitment}

Recruitment is crucial. We need to recruit for the right mindset, attitudes and ability. But how do you encourage people to apply in the first place?

The University launched the Chancellor's Fellowship scheme in 2012 to recruit 100 people who had the potential to be future research leaders in their fields. Two-thirds of the appointments were men. But two thirds of the people who applied were also men. It is very hard to address gender imbalances when the starting point is a very imbalanced pool of potential applicants.

This isn't limited to academic roles.

[The University is] a large tech employer and we compete for staff with other tech companies in Edinburgh. We have the same problems that they do in retaining women. Our career paths are not clear, we have no graduate recruitment programme and few visible women in senior management roles. We are working hard to get our job adverts seen by a more diverse set of people and rethinking recruitment strategies.

\section{Promotion and reward}

The gender imbalance of the applicant pool also applies to promotions.

The percentage of women and men who are successful in promotion is the same. The number of men and the number of women who put themselves forward is dramatically different.

Even once women do reach the senior grades, there can be very different salary levels. While people appointed externally rather than promoted internally can have more opportunity to negotiate salaries, there are clear gender imbalances in pay.

As a head of school, the thing which most shocked me is massive disparity in salary levels. Men have often demanded larger salary packages. Your salary is influenced by what you ask for when 
you come in, what your previous salary was. All of this results in a big gap.

University of Edinburgh salary gender figures can be found in: http://www. docs.csg.ed.ac.uk/EqualityDiversity/ Equal_Pay_Report_2015.pdf.

Another person added:

Women tend to be more modest - they don't know what others are on and what is reasonable to ask for. If you have different salary expectations early in your career and new job offers are based on previous salaries, there is a cumulative effect.

People are willing to take action to redress this:

We have tried to be proactive with this as much as the structures allow, particularly awarding additional increments.

But there are limits to how much a salary can be adjusted once someone is in post. It could take many years to reach parity.

It is also important that there is a sense of fairness to all members of staff.

There is also a disparity for reward processes for support staff. It can be very challenging to get even a small contribution award for junior admin staff members. Staff can feel like they aren't valued [if they aren't an academic].

\section{Workload allocation and flexible working}

Day to day working patterns and expectations around workload can be hard to balance.

How you use and what you do with your workload models are a double-edged sword. They can help but they can also hinder.

There were also reflections about the level of work staff were asked to do.

[We] need to look at workloads for everyone. Are we asking colleagues to do things which are just not possible in a 9-5 working week?
As managers, people found it hard to tackle a long-hours culture:

It is hard to prevent it as those who want to work long hours will. But they will probably do more stuff and will probably be promoted more quickly so in effect you are rewarding that behaviour.

This can put more pressure on people to feel that they have to also work very long hours. Not everyone can or wants to do this. The perceived costs of career progression can increase and in some cases outweigh the benefits. This may put talented and capable people off developing their careers further.

In addition to long hours, flexible working had its challenges.

Athena SWAN can be a double-edged sword. In my department, it has been quite divisive between female support staff and female academics. Flexible working arrangements are there for academics but what about for professional services staff?

In other sectors, men have faced stigma in requesting flexible working.

Even when flexible working or part-time requests are granted, they can be difficult to manage in practice. The nature of the work can be hard to adjust to parttime and expectations of colleagues (real or perceived) can mean people feel under significant pressure or that they are never quite doing 'enough'.

The challenges of reconciling long hours and flexibility was touched on several times and it came back to the wider point of rethinking what careers should look like:

We need to particularly look at career structures across the board. As long as we think about 'pipelines' as a vision of career, it's not particularly helpful. We need a different mindset which is more relevant to flexible careers - scale up, scale down, what happens outside work, what happens in work.

287 EqualBITE Leadership perspectives on gender equality 
A broader view of careers is something which could benefit everyone.

\section{Performance management}

It is never enjoyable to tackle performancerelated issues. However, several managers described the dilemma they felt in this aspect of their role.

It is a pressurised position. Challenging poor performance can take you into dangerous territory if the person not performing is a woman or from a minority group. There is a risk that your actions will be viewed as discrimination - and it can put you off tackling a performance issue.

There was also an acknowledgement that the level of support from HR had improved over the years and there was more confidence in handling these issues appropriately.

\section{Internal drivers: creating a culture based on trust and respect}

While establishing workplace policies and action plans to enhance equality are not in themselves sufficient to change the culture, they play a vital role in highlighting the issue and examples of acceptable and appropriate behaviour. This can help people to feel more confident to take action individually.

You need an environment where people feel safe to challenge inappropriate behaviour. you need trust. People need to feel they can talk about it and be listened to.

Creating an inclusive culture takes effort and courage.

[Where] there is a disparity of gender and power, if it is not called out, it sets the culture where that imbalance is OK.

However, it isn't easy to continually challenge seemingly minor incidents particularly:

To call out behaviours with colleagues who don't think they are like that.
Another person spoke of the security a more senior role provided:

There is a risk when you do call out bad behaviour - there is a backlash. I wouldn't be able to call out bad behaviour until I got to this level of seniority. And now I am at this level I feel I have a responsibility to.

Several people shared the sense of responsibility they felt they had in a leadership role.

The biggest thing I've learned as head of school, you have to lead by example. If you want something to be adopted, you have to do it and pay attention to it. People look to what you do, not what you say.

Another senior woman added:

Once you get to a certain level, there is much more support. You feel you have responsibilities to support junior colleagues.

Reflecting on the 'drip, drip, drip' of negative comments, one person stressed the need to:

Reflect on the automatic things you do. Once people are openly talking, senior managers set the tone, culture, everyone speaks out. It is about being human.

Another woman said it is about:

Giving back; what made a difference to you can help counter some of the other stuff. You need male role models too.

The importance of diverse role models and a positive attitude was mentioned several times.

There is a general forward direction of travel. We shouldn't beat ourselves up about apparent lack of progress. There is now, in my area, a critical mass and variation offemale role models. It is good for students to see there are many ways to be a successful female scientist.

We always talk about the negative side of imbalances, there should be more focus on positive experiences - it 
is harder to get that out. We need to avoid shooting ourselves in the foot; we need to talk about what is positive.

In some areas there was a sense, several years on from the first Athena SWAN initiatives and other policies, that there had been a shift.

Coffee-room conversations can be dangerous ground. Now, discriminatory talk is called out and challenged by colleagues. You wouldn't have seen this 10 years ago. It is important that everyone does this, not just one person who is then seen as a nag.

\section{Changing Expectations and Habits}

People also provided examples of how some polices had become default habits. One person particularly stressed:

Email and the timing of email. We have a new email etiquette in the schoolwhat is and what isn't appropriate. No expectation of emails between $5 \mathrm{pm}$ and then gam the next morning.

Another head of school said:

I have a strapline on my email - I don't expect an answer outside normal working hours.

Reflecting on experiences of recruitment, another person added:

I've been more aware of obstacles people may have faced in their career... It is hard not to make assumptions. The weakness we have in the school is getting people not to make assumptions, everyone involved in recruitment has to have training regarding unconscious bias and E\&D [equality and diversity].

\section{Looking ahead}

The sheer increase in numbers of women is helping. Not at senior levels yet but there is more awareness; it is talked about more often. There is more training on things you can do as a manager.
While there was a sense from most people that there had been positive change, this did come with some caveats.

Universities shouldn't be complacent. There is an absolute need for reflective practice.

Looking to the future, the priorities for senior leaders were to avoid complacency, protect progress made so far, appreciate and celebrate successes and continue to drive for change.

The world is changing but it takes time. We need to be careful we don't revert back, we need to look at long term effects.

Another person said:

We appointed over 100 Chancellor's Fellows. There was no gender pay gap when they were appointed. It would be interesting to see in five years and beyond if a gender pay gap opens up. It goes back to data: what you can put in place and then measure.

They went on to stress that:

Ownership is crucial. People need to take action. And to do that they need resources - money and time.

Gender inequality is pervasive [in our society] - in my view it's not really changing. The least we can do is work within the institution. But new power structures are fragile: you need to keep your foot on the pedal. 


\section{Focus group participants}

Chris Breward is Professor of Cultural History, Principal of Edinburgh College of Art and Vice-Principal Creative Industries and Performing Arts.

Sarah Cunningham-Burley is Professor of Medical and Family Sociology and Assistant Principal Research-led Learning. Sarah is also Dean of Molecular, Genetic and Population Health Sciences, Edinburgh Medical School.

Shelagh Green is Director of Careers and Employability and President of the national Association of Graduate Careers Advisory Services (AGCAS).

Melissa Highton is Director of Learning, Teaching and Web Services and Assistant Principal Online Learning.

Alan Murray is Professor of Neural Electronics, Assistant Principal Academic Support and Head of the BioEngineering Research Institute. Alan is a former Head of School of Engineering.

Colin R Pulham is Professor of High-Pressure Chemistry and Head of School of Chemistry

Kathryn A Whaler is Professor of Geophysics and Deputy Head of School of GeoSciences. Kathy is a former Head of Department for Geology and Geophysics and a former Head of Institute of Earth and Planetary Sciences.

Lesley Yellowlees is Professor of Inorganic Electrochemistry and Vice-Principal and Head of the College of Science and Engineering. Lesley is a former Head of the School of Chemistry. 